\title{
Diagnostic Efficacy of Rapid Immunochromatographic Test in Diagnosis of Dengue Infection
}

\author{
Charanjeev Kaur* (iD) and Sarbjeet Sharma \\ Department of Microbiology, Sri Guru Ram Das Institute of Medical Sciences and Research, \\ Amritsar, Punjab, India.
}

\begin{abstract}
Dengue is a mosquito-borne arboviral disease of grave public health concern worldwide. Early diagnosis and treatment is required to reduce morbidity \& mortality from complications caused by secondary dengue infection. According to WHO, the three main diagnostic modalities for the diagnosis of dengue infection are cultivation and identification of viruses, molecular methods, and serology. Whereas virus cultivation is labour intensive and available only in reference laboratories, molecular methods require expensive infrastructure \& expertise. Serology on the other hand not only less tedious but is also able to differentiate between primary and secondary dengue. This study was undertaken to evaluate the diagnostic efficacy of rapid immunochromatographic assay in the diagnosis of dengue infection as compared to ELISA. The study was conducted in the serology section of the Microbiology laboratory, Sri Guru Ram Das Institute of Medical Sciences, Amritsar. Blood samples from 429 patients with clinical suspicion of dengue virus infection were received in the lab from August 2020 to December 2020. All samples were subjected to rapid ICT and ELISA to detect NS1 Ag and IgM antibodies. The majority number of cases were observed in the age group of $\mathbf{3 1}$ to $\mathbf{4 0}$ years while the gender-wise ratio was 1.43:1 showing male preponderance. Out of 429 samples tested, 156 were reactive for either NS1 antigen or IgM antibodies by the ELISA method. Results of rapid ICT for NS1Ag and results of NS1Ag by ELISA were analyzed and compared. A sensitivity of $81.25 \%$ was noted and specificity of $100 \%$. IgM detection by rapid ICT in comparison to IgM ELISA shows a sensitivity of $82.14 \%$ and specificity of $100 \%$. Rapid ICT kits performed at par with the ELISA. Rapid immunochromatographic assays are important diagnostic tools in the identification of dengue and early treatment of dengue patients is possible, reducing mortality significantly.
\end{abstract}

Keywords: Dengue, Rapid Immunochromatographic test, ELISA

\footnotetext{
*Correspondence: drcharanjeev@gmail.com; +91 9878890027
}

(Received: August 8, 2021; accepted: January 4, 2022)

Citation: Kaur C, Sharma S. Diagnostic Efficacy of Rapid Immunochromatographic Test in Diagnosis of Dengue Infection. J Pure Appl Microbiol. 2022;16(1):448-452. doi: 10.22207/JPAM.16.1.42

(C) The Author(s) 2022. Open Access. This article is distributed under the terms of the Creative Commons Attribution 4.0 International License which permits unrestricted use, sharing, distribution, and reproduction in any medium, provided you give appropriate credit to the original author(s) and the source, provide a link to the Creative Commons license, and indicate if changes were made. 


\section{INTRODUCTION}

Dengue also called break-bone fever, is caused by a virus belonging to the genus Flavivirus which is an Arbovirus. ${ }^{1}$ It is a mosquito-borne virus. Female mosquitoes mainly Aedes aegypti and Aedes albopictus are the vectors of this virus. ${ }^{2}$ These mosquitoes are vectors for some other diseases like zika fever, yellow fever, chikungunya etc. ${ }^{1}$ Dengue virus is from family Flaviviridae. It has four serotypes namely DENV-1, DENV-2, DENV-3, and DENV-4, which are responsible for causing Dengue. Infection of one serotype provides lifelong immunity against that specific serotype but there is no or very less cross-immunity to other serotypes. ${ }^{3}$ Secondary infection by other serotypes leads to the development of serious disease e.g dengue hemorrhagic fever. ${ }^{1}$

Pre-existing dengue antibodies are liable for severe disease. Within few days of the second dengue infection, Virus-antibody complexes are formed. A large number of mononuclear cells are infected by these non-neutralizing, enhancing antibodies, which result in the release of cytokines, vasoactive mediators, and procoagulants causing disseminated intravascular coagulation which causes dengue hemorrhagic fever syndrome. ${ }^{4}$

Around 3.9 billion of the population are under threat of dengue infection worldwide, maximum risk in the tropical region especially Southeast Asia and western pacific. ${ }^{1}$

An early diagnosis of the Dengue virus should be done for rapid treatment of the disease and also rule out other differential diagnoses. According to WHO virological and/or serological tests must be performed for the diagnosis of dengue. Virological methods include isolation of the virus, virus nucleic acid detection by RT-PCR. Whereas serological methods include identification of a protein, NS1 antigen which is produced by the virus. Other than the ELISA method, which according to WHO is the diagnostic test for diagnosis of dengue, Rapid diagnostic kits, which are immunochromatographic tests (ICT) assay are also available for this. These rapid ICT assay do not require trained staff or costly and highly equipped labs. These rapid ICT assay give results within 20 minutes. Serological methods also detect IgG and IgM anti-dengue antibodies. IgM antibodies are detectable 1 week after infection and are highest at 2 to 4 weeks after the onset of illness suggesting a recent infection. They can be detected till 3 months post-infection in the serum. ${ }^{5-7}$

Hence either the rapid ICT assay or ELISA test can be performed to detect the presence of NS1 or Ig M antibodies in the serum of the patient. Rapid diagnostic tests which are non-ELISA-based immunochromatographic tests (ICT) are less reliabale. ${ }^{8}$ There are different reports regarding sensitivity and specificity of ICT. This study aims to determine and evaluate rapid diagnostic test for NS1 Ag and IgM antibody for diagnosis of dengue in comparison to ELISA tests in terms of diagnostic efficacy, sensitivity, and specificity of rapid ICT kits used in our hospital.

\section{MATERIALS AND METHODS}

The present study was carried out at the Microbiology department, Sri Guru Ram Das Institute of Medical Sciences, Amritsar, during the 2020 dengue season (August; 2020 to December; 2020) in Amritsar, India. Blood samples of 429 patients suspected of DENV infection were received in the lab. These patients were of all age groups. Serum was separated from these samples and further analyzed. Each serum sample was tested for both rapid immunochromatographic assay (SD Biosensor Dengue Ag + Ab Duo) manufactured by SD Biosensor Healthcare Pvt. Ltd., India which detects NS1 antigen, IgM and IgG antibodies and ELISA (ERBA Lisa Scan EM \& Lisa Wash) for detecting NS1antigen and IgM Capture Elisa for IgM antibodies. Data regarding NS1 antigen and IgM antibodies were compiled and analyzed statistically.

\section{Ethical Clearance}

Approval from the ethical committee of the institute was obtained for the study. Ref No.SGRD/IEC/2021-07

\section{Statistical Analysis}

Data collected was analyzed with MedCalc statistical software version 20.0.4.

\section{RESULTS}

A total of 429 samples of suspected dengue patients were received in the microbiology lab. The age group that showed the highest seropositivity was 31 to 40 years, next to this group was 21 to 30 years age group. (Table 1). Genderwise distribution is shown in Table 2. Out of total 
Table 1. Age-wise distribution

\begin{tabular}{lcc}
\hline $\begin{array}{l}\text { Age } \\
\text { (Years) }\end{array}$ & $\begin{array}{c}\text { No. of } \\
\text { cases }\end{array}$ & $\%$ \\
\hline$<10$ & 6 & $3.84 \%$ \\
$11-20$ & 15 & $9.61 \%$ \\
$21-30$ & 37 & $23.71 \%$ \\
$31-40$ & 43 & $27.56 \%$ \\
$41-50$ & 27 & $17.30 \%$ \\
$51-60$ & 17 & $10.89 \%$ \\
$61-70$ & 10 & $6.41 \%$ \\
$>70$ & 2 & $1.28 \%$ \\
TOTAL & 156 & \\
\hline
\end{tabular}

Table 3. Comparison of ELISA and rapid ICT for NS1 Ag

\begin{tabular}{lccc}
\hline & $\begin{array}{c}\text { ELISA } \\
\text { Positive }\end{array}$ & $\begin{array}{c}\text { ELISA } \\
\text { Negative }\end{array}$ & TOTAL \\
\hline Rapid positive & 104 & 0 & 104 \\
Rapid negative & 24 & 301 & 325 \\
& 128 & 301 & \\
Sensitivity & & $81.25 \%$ & \\
Specificity & & $100 \%$ & \\
PPV & & $100 \%$ & \\
NPV & & $92.61 \%$ & \\
DA & & $94.40 \%$ & \\
\end{tabular}

samples tested male to female ratio was 1.43:1 showing male preponderance.

Out of 429 samples tested, 156 samples were reactive for either NS1 Ag or IgM antibodies by the ELISA method and 127 were found to be positive for dengue infection by rapid ICT assay. The samples tested with rapid ICT and IgM ELISA and comparison of these tests showed that of the total 429 samples, 127 were positive and 301 were negative by both the tests. There were 24 samples which were positive by ELISA and negative by rapid ICT for NS1 Ag and 5 samples were positive by ELISA and negative by ICT for IgM and were considered false negative.

The sensitivity of the rapid ICT assay for NS1Ag was $81.25 \%$ and it was $100 \%$ specific. The positive predictive value of rapid ICT assay for $\mathrm{NS} 1 \mathrm{Ag}$ is $100 \%$ and a negative predictive value of $92.61 \%$ was noted for the same, while data accuracy was calculated to be $94.40 \%$. (Table 3 )

Table 4 depicts a comparison of IgM detection by rapid ICT with IgM ELISA, showing sensitivity $82.14 \%$, specificity $100 \%$, positive
Table 2. Gender wise distribution of dengue positive case

\begin{tabular}{lcc}
\hline Sex & Number & $\%$ \\
\hline Male & 92 & $58.97 \%$ \\
Female & 64 & $41.02 \%$ \\
Total & 156 & \\
\hline
\end{tabular}

Table 4. Comparison of CAPTURE ELISA and rapid ICT for IgM

\begin{tabular}{lccc}
\hline & $\begin{array}{c}\text { ELISA } \\
\text { Positive }\end{array}$ & $\begin{array}{c}\text { ELISA } \\
\text { Negative }\end{array}$ & TOTAL \\
\hline Rapid positive & 23 & 0 & 23 \\
Rapid negative & 5 & 401 & 406 \\
& 28 & 401 & \\
Sensitivity & & $82.14 \%$ & \\
Specificity & & $100 \%$ & \\
PPV & & $100 \%$ & \\
NPV & & $98.76 \%$ & \\
DA & & $98.83 \%$ & \\
\hline
\end{tabular}

predictive value $100 \%$, and negative predictive value of $98.76 \%$ while data accuracy of $98.83 \%$ was observed.

\section{DISCUSSION}

Dengue is prevalent worldwide, but southeast Asia and Latin America are the hot spots of dengue. Other febrile illnesses caused by mosquito-borne viruses like Zika or Chikungunya have similar signs and symptoms which resemble those of dengue. Some of such symptoms are fever, myalgias, maculopapular rash, retro-orbital pain, and lymphadenopathy. Thus making it difficult to diagnose without laboratory investigations. ${ }^{5}$ Many rapid immunochromatographic test assays for detecting dengue NS1, IgM and IgG antibodies are available and many studies have evaluated their performances. In this study, the performance of ICT (SD Biosensor Dengue Ag +Ab Duo) used in our hospital in comparison to MAC-ELISA (ERBA Lisa Scan EM \& Lisa Wash, Germany) was compared.

In this study 429 serum samples of suspected dengue patients were tested by rapid ICT and ELISA for both NS1 antigen and IgM antibodies. The foremost common cohort affected was 20 to 40 years. Similar results were given by Sarah Hassan et al. ${ }^{9}$ Also these results are in line 
with the study by Garg et al. ${ }^{10}$ which observed that the median age was 35.5 years.

The study also showed male predominance, Garg et al., ${ }^{10}$ Tabasum MB et al., ${ }^{7}$ Annapurna SL et al., ${ }^{11}$ observed similar results while on the contrary Anand AM et al., ${ }^{3}$ showed male to female ratio of $1: 1.35$.

In our study, rapid ICT assay for NS1 Ag and IgM shows sensitivity more than $80 \%$ and specificity $100 \%$ compared to ELISA. Another study by Reddy RM showed over $90 \%$ sensitivity and over $98 \%$ specificity ${ }^{12}$ While studies conducted in various hospitals recorded a good range of sensitivity of rapid ICT for NS1 Ag 49.4\%-98.9\% and specificity starting from $91 \%-100 \% .^{13}$

Sensitivity of $82.14 \%$ and specificity of $100 \%$ were observed in our study for IgM antibody detection by rapid ICT in comparison to ELISA during this study. These results are slightly different from those observed in another study by Hassan S et al. ${ }^{10}$ While a study conducted in Srilanka shows a sensitivity of $64 \%$ and specificity of $74.7 \%$ of anti-DEN V IgM detection by rapid ICT. ${ }^{14}$ This difference in reported sensitivity and specificity could be because of different commercial assays used in different studies. ${ }^{11}$ In the present study $100 \%$ Positive predictive value of rapid ICT for NS1 Ag and IgM is noted. Positive predictive value is the probability that subjects with a positive screening test truly have the disease so there was no need for confirmatory testing. Similar findings were noted by several other authors Garg et al., ${ }^{10}$ Shih et al. ${ }^{15}$ The study shows that the sensitivity of rapid card test is less but has a good specificity. In situations of epidemic, the card test can be used for screening but with the support of IgM capture ELISA. ${ }^{16}$

Virus cultivation is labour intensive and available only in reference laboratories while molecular methods require expensive infrastructure \& expertise. Serology on the other hand not only less tedious but is also able to differentiate between primary and secondary dengue.

Rapid Immunochromatographic test assay is an easy and simple procedure, no special equipment or no trained staff is required This test is cost-effective because many samples are to be put together for ELISA to be cost-effective, which increases its turnaround time. Rapid ICT assay can be performed on a single sample as soon as the sample is received within the lab. Rapid ICT results are available within 15 to 20 minutes. Our study found that rapid ICT assay that we used for NS1 Ag and IgM performed at par with ELISA-based tests. But in step with the definition given by WHO of confirmed cases, all cases which are screened by rapid ICT assay should be confirmed by ELISA. ${ }^{1}$

\section{CONCLUSION}

In resource-limited countries, which lack diagnostic laboratories with types of equipment for PCR, virus isolation, or ELISA, esp in remote and rural areas, rapid ICT assay is an important diagnostic test of dengue and early management of such patients is feasible, reducing the mortality significantly.

\section{ACKNOWLEDGMENTS}

The authors would like to express their heartfelt thanks to Dr Sahiba Kukreja for providing assistance with statistics.

\section{CONFLICT OF INTEREST}

The authors declare that there is no conflict of interest.

\section{AUTHORS' CONTRIBUTION}

Both the authors have made a substantial, direct and intellectual contribution to the work, and approved it for publication.

\section{FUNDING}

None.

\section{DATA AVAILABILITY}

The data analysed during the study are available from the corresponding author on reasonable request.

\section{ETHICS STATEMENT}

This study was approved by the Institutional Ethics Committee, Sri Guru Ram Das Institute of Medical Sciences and Research, Punjab, India (Ref No. SGRD/IEC/2021-07).

\section{REFERENCES}

1. WHO. Dengue and severe dengue. 2021. https://www. who.int/news-room/fact-sheets/detail/dengue-andsevere-dengue. Accessed 8 July 2021. 
2. Sumana MN, Linda RJ, Tabasum BM. Seroprevalence of Dengue and Leptospira co-infection in Mysore, Karnatka: A study in children at a tertiary care hospital. International Journal of Interventions in Pharmaceutical Sciences.2014;2(3):774-778.

3. Anand AM, Sistla S, Dhodapkar R, Hamide A, Biswal $\mathrm{N}$, Srinivasan B. Evaluation of NS1 Antigen Detection for Early Diagnosis of Dengue in a Tertiary Hospital in Southern India. J Clin Diag Res. 2016;10(4):DC01-DC04. doi: $10.7860 / J C D R / 2016 / 15758.7562$

4. Jawetz, Melnick, Adelberg's Medical Microbiology. $27^{\text {th }}$ Edition. McGraw Hill Education. 552-554.

5. Shrivastava A, Dash PK, Tripathi NK, Sahni AK, Gopalan N, Lakshmana Rao PV. Evaluation of a commercial dengue NS1 enzyme-linked immunosorbent assay for early diagnosis of dengue infection. Indian J Med Microbiol. 2011;29(1):51-55. doi: 10.4103/02550857.76525

6. Kumarasamy V, Wahab AH, Chua SK, et al. Evaluation of a commercial dengue NS1 antigen-capture ELISA for laboratory diagnosis of acute dengue virus infection. Journal of Virological Methods. 2007;140(1-2):75-79. doi: 10.1016/j.jviromet.2006.11.001

7. Begum MT, Sumana MN, Gowdappa HB. Evaluation of Rapid ICT in comparison with MAC-ELISA in diagnosis of dengue fever at a tertiary care hospital, South India. Int J Pharm Sci Invent. 2014;3(12):11-16.

8. Shastry AS, Bhat SK. Essentials of medical microbiology. $3^{\text {rd }}$ Edition. Jaypee Brothers Medical Publishers $(p)$ Ltd. 2021:340.

9. Chan HBY, How CH, Mark Ng CW. Definitive tests for dengue fever: when and which should I use? Singapore Med J. 2017;58(11):632-635. doi: 10.11622/ smedj.2017100

10. Garg A, Garg J, Singh DV, Dhole TN. Can rapid dengue diagnostic kits be trusted? A comparative study of commercially available rapid kits for serodiagnosis of dengue fever. J Lab Physicians. 2019;11(01):63-67. doi: 10.4103/JLP.JLP_140_18

11. Annapoorna SL, Kavitha Latha ML, Shanker. Clinical, microbiological profile of dengue cases reported at a tertiary care hospital in Telangana, India. Trop J Path Micro. 2019;5(11):899-902. doi: 10.17511/jopm.2019. i11.11

12. Reddy RM, Sahai K, Malik A, Shoba S, Khera A. Comparative Analysis of Rapid Dengue Testing and ELISA for NS1 Antigen and IgM in Acute Dengue Infection. Int J Curr Microbiol App Sci. 2016;5(10):931937. doi: 10.20546/ijcmas.2016.510.100

13. Mata VE, Ferreira de Andrade CA, Passos SRL, Hokerberg YHM, Fukuoka LVB, Alves da Silva S. Rapid immunochromatographic tests for the diagnosis of dengue: a systematic review and meta-analysis. Cad Saude Publica 2020;36(6):e00225618. doi: 10.1590/0102-311x00225618

14. Muruganathan K, Coonghe PAD, Ketheesan N, Noordeen F. Comparison of a rapid immunochromatography assay with a standard ELISA for the detection of IgM and IgG antibodies against dengue viruses. Virus Dis. 2018;29(2):199-202. doi: 10.1007/ s13337-018-0440-x

15. Shih HI, Hsu HC, Wu CJ, et al. Application of a Rapid and Sensitive Dengue DUO Rapid Immunochromatographic test Kit as a Diagnostic Strategy during a Dengue Type 2 Epidemic in an Urban City. Plos One. 2016;11(7):e0158437. doi: 10.1371/journal. pone. 0158437

16. Pramiladevi R, Kaivalya, Kora S. Study of rapid serological tests for diagnosis of Dengue. Sch J App Med Sci. 2003;1(5):548-551. 